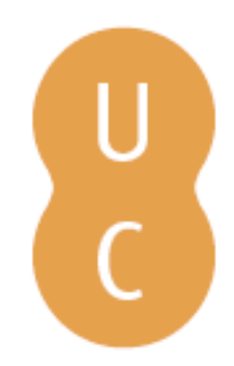

\title{
nommalina
}

\section{Doutrinas não-escritas}

Autor(es): $\quad$ Mesquita, António Pedro

Publicado por: Imprensa da Universidade de Coimbra

URL

persistente: URI:http://hdl.handle.net/10316.2/44239

DOI: $\quad$ DOl:https://doi.org/10.14195/978-989-26-1596-7_3

Accessed : $\quad$ 26-Apr-2023 14:06:35

A navegação consulta e descarregamento dos títulos inseridos nas Bibliotecas Digitais UC Digitalis, UC Pombalina e UC Impactum, pressupõem a aceitação plena e sem reservas dos Termos e Condições de Uso destas Bibliotecas Digitais, disponíveis em https://digitalis.uc.pt/pt-pt/termos.

Conforme exposto nos referidos Termos e Condições de Uso, o descarregamento de títulos de acesso restrito requer uma licença válida de autorização devendo o utilizador aceder ao(s) documento(s) a partir de um endereço de IP da instituição detentora da supramencionada licença.

Ao utilizador é apenas permitido o descarregamento para uso pessoal, pelo que o emprego do(s) título(s) descarregado(s) para outro fim, designadamente comercial, carece de autorização do respetivo autor ou editor da obra.

Na medida em que todas as obras da UC Digitalis se encontram protegidas pelo Código do Direito de Autor e Direitos Conexos e demais legislação aplicável, toda a cópia, parcial ou total, deste documento, nos casos em que é legalmente admitida, deverá conter ou fazer-se acompanhar por este aviso.

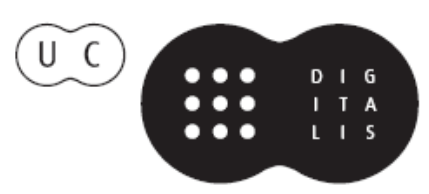




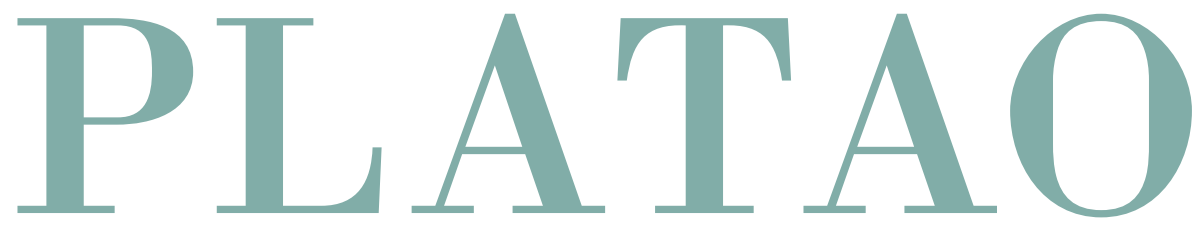

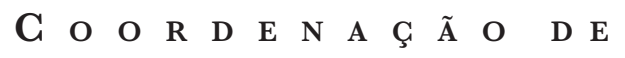
G A B R I E L E C O R N E L L I E R O D O L F O L O P E S

\section{CoimbraCompanions}




\section{III}

DOUTRINAS NÃO-ESCRITAS

António Pedro Mesquita

Centro de Filosofia da Universidade de Lisboa

DOI | https://doi.org/10.14195/978-989-26-1596-7_3 
No conjunto de controvérsias que dividiram a exegese platónica dos últimos cinquenta a cem anos, como a chamada 'questão socrática', o problema da unidade ou evolução do pensamento platónico ou o da cronologia dos diálogos, aquela que ainda hoje se afigura como mais fracturante é seguramente a das 'doutrinas não-escritas'.

O motivo principal da pertinácia historicamente demonstrada por esta controvérsia deve-se ao facto de existir no interior dos comentadores de Platão uma corrente, minoritária, mas influente - a chamada 'escola de Tübingen' ou 'de Tübingen-Milão', onde se destacam Hans-Joachim Krämer, Konrad Gaiser e, mais recentemente, Thomas Szlezak e Giovani Reale -, para quem a verdadeira filosofia platónica corresponde à das suas 'doutrinas não-escritas', por oposição àquelas escritas nas suas obras publicadas, os diálogos.

No presente texto, gostaria de contribuir para uma reavaliação desta controvérsia e, em especial da posição nela assumida pela escola de Tübingen, na perspectiva de determinar qual o valor que deve ser respectivamente atribuído aos diálogos platónicos e às reconstituições modernas das alegadas

1 O presente texto constitui uma versão revista e actualizada de uma secção do estudo Reler Platão. Ensaio sobre a Teoria das Ideias (Mesquita, 1995). 
doutrinas não-escritas de Platão como modo de acesso privilegiado à filosofia do Mestre Ateniense.

\section{II}

Sem ter a pretensão de fazer a história desta questão, que, de qualquer modo, já está feita², será talvez útil começar por recordar alguns dos seus marcos, sobretudo porque, embora a polémica seja recente, os factos e as interpretações em que se alimenta são antigos.

Tudo começa, como é frequente, com Aristóteles.

Com efeito, de entre os comentadores platónicos da primeira geração,

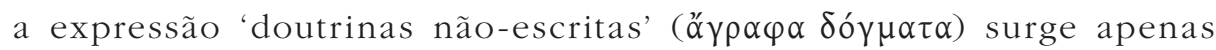
testemunhada pelo Estagirita na Física ${ }^{3}$, no contexto da discussão do conceito de lugar, para cujo esclarecimento Aristóteles convoca o ensinamento de Platão no Timeu, que ele interpreta na perspectiva de uma identificação da $\chi \omega ́ \rho \alpha$ com a matéria. Todavia, logo de seguida acrescenta que é diferente

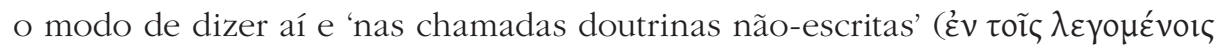

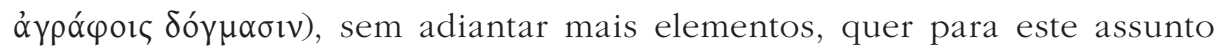
em concreto, designadamente sobre o conteúdo de tais doutrinas, quer, em geral, para a noção das 'doutrinas não-escritas', quer ainda para a relação destas com as obras platónicas escritas.

Curiosamente, portanto, embora seja esta a primeira (e, na época, única)

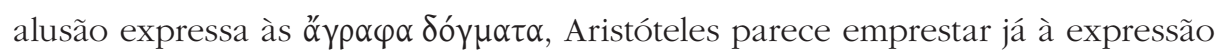
um certo aspecto convencional, ao referir-se-lhes como 'as chamadas doutrinas não-escritas', o que tanto pode sugerir a sua familiaridade junto do leitor e o carácter corrente e tradicional da designação, quanto, numa interpretação menos valorativa (que é a de alguns autores que adiante

2 E pode ser consultada, nos seus desenvolvimentos modernos, na obra de MarieDominique Richard (1986), L'enseignement oral de Platon (com maior destaque conferido aos pensadores de Tübingen, de que a autora se aproxima, e respectiva documentação), bem como no extenso ensaio (mais antigo) de C. De Vogel (1988), 'Plato: The Written and Unwritten Doctrines'. Uma síntese comentada das questões envolvidas encontra-se também no quinto volume da History of Greek Philosophy de Guthrie (1978, 418-442). 
revisitaremos), as próprias reservas de Aristóteles em relação a uma designação que considerava inadequada.

Um segundo testemunho importante, porque sempre invocado pelos defensores de um ensino oral regular e 'dogmático' de Platão e, portanto, sempre na tona da polémica, é a anedota registada por um discípulo directo do Estagirita, Aristóxeno de Tarento, nos seus Elementa Harmonica ${ }^{4}$, em que este alega ter ouvido contar ao próprio Aristóteles o mau acolhimento que uma lição de Platão sobre o bem teria tido junto do público, por, ao invés de discorrer acerca dos bens comummente reconhecidos, como a saúde e a riqueza, ter preferido versar de aritmética, geometria e astronomia, defraudando assim as suas expectativas iniciais 5 .

A importância desta referência, em si mesma oblíqua e menor, à

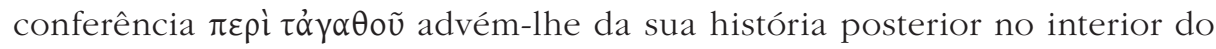
comentário aristotélico e, em especial, dos relatos de Simplício, onde, por um lado, o seu conteúdo surge presumivelmente clarificado ${ }^{6}$, e, por outro, se faz menção, não já a uma única lição, mas a um conjunto de discursos

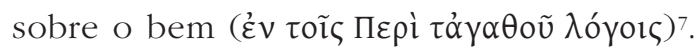

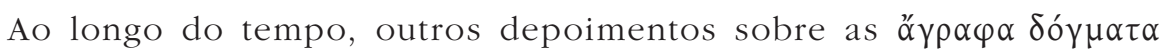
platónicas foram-se acumulando no interior da tradição peripatética e da tradição neoplatónica ${ }^{8}$, fomentados e alimentados também pela própria letra

4 Aristox. Harm. 39.

5 Eis a transcrição: "A maior parte dos que escutaram o curso de Platão acerca do bem ficaram afectados. Na verdade, quem quer que lá tivesse ido supunha que ia aprender algo acerca do que se considera um bem humano, tal como a riqueza, a saúde, o vigor e, em geral, a possibilidade de uma felicidade espantosa. Quando, porém, se começou a falar de matemática, acerca de números, de geometria e de astrologia e do limite como sendo o único bem, penso que tudo lhes apareceu como um contra-senso. Logo de seguida, uns começaram a desprezar a matéria em discussão, outros ainda a censurá-la.' (trad. Caeiro, 2014).

6 In $\mathrm{Ph} .151 .6-11$ e 453.23-454.21 Diels (= fr. 28 Rose).

7 In $\mathrm{Ph} .453 .28$ Diels.

8 Os testemunhos começaram a ser reunidos por Konrad Gaiser nos seus Testimonia Platonica (1998), primitivamente publicados em apêndice a Platons ungeschriebene Lebre (1963), e depois por Margherita Isnardi Parente em duas obras sucessivas com o mesmo título, dedicadas, respectivamente, aos testemunhos aristotélicos e aos dos períodos helenístico e imperial (1997; 1998). Os textos principais constam também na obra de Marie-Dominique Richard (1986), L'enseignement oral de Platon. 
da obra platónica conservada, onde são recorrentes as reservas em relação à palavra escrita ${ }^{9}$.

Assim se desembocou numa vexata quaestio da erudição platónica que o século XIX começou a debater com alguma insistência e que se tornou, logo no início do século passado, numa das encruzilhadas privilegiadas da interpretação de Platão.

Nela, três pontos são, porém, suficientemente claros:

1) a atribuição de doutrinas não-escritas a Platão tem uma origem textual em Aristóteles, a qual, apesar de não expressamente confirmada pelo corpus platónico, pode ser-lhe indirectamente reportada pelas suas reiteradas críticas à escrita;

2) a importância conferida a essas doutrinas deve-se sobretudo à tradição posterior;

3) a tradição constitui simultaneamente o único testemunho explícito acerca

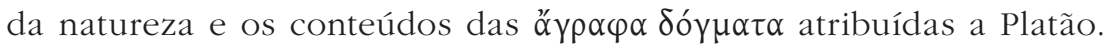

Ora este último ponto remete-nos para o problema crucial.

É que, não havendo nenhuma discriminação por parte de Aristóteles do teor das ó $ү \rho \alpha \varphi \alpha \delta$ ó $\mu \alpha \tau \alpha$ platónicas no único momento em que delas fala, na passagem mencionada da Física, ficamos dependentes dos relatos posteriores para o conhecimento dos tópicos sobre os quais versaria a alegada doutrina não-escrita de Platão. E tais tópicos, muito em virtude da discrepância evidente entre as descrições que, noutros locais, Aristóteles oferece da filosofia platónica e aquela que nos é apresentada pelo próprio Platão no interior dos diálogos, são feitos unanimente consistir pela referida tradição nos constantes dessas mesmas descrições aristotélicas.

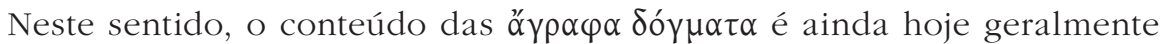
considerado como idêntico a tais descrições, na exacta medida em que elas

9 A inadequação da palavra escrita é, de facto, uma advertência constante de Platão, particularmente no Protágoras 329a, 347b-348b (cf. Hp. Mi. 365cd), no Fedro 274b-277a, nas Leis XII 968ce e na Carta VII 341c-344e, bem como na, provavelmente apócrifa, Carta II, $313 \mathrm{c}-314 \mathrm{c}$, que a repete abundantemente, atravessando, pois, os três períodos por que é usual distribuir-se a obra platónica. 
não correspondem, pelo menos aparentemente, ao que se poderia retirar de uma leitura directa dos diálogos.

Daí a ambição que de alguns quadrantes emergiu, principalmente no século precedente, de elaborar uma reconstrução do pensamento platónico a partir dos testemunhos aristotélicos, sobretudo tendo em atenção que as reservas de Platão relativamente à linguagem escrita e a sua declarada preferência pela oralidade poderia garantir uma maior fidelidade de tal reconstrução em relação ao 'verdadeiro platonismo' do que a própria obra escrita deste.

De acordo com essas tentativas de reconstrução, tais testemunhos, disseminados em diversos passos da obra aristotélica ${ }^{10}$, permitiriam assegurar que o ensinamento platónico não-escrito, diferentemente do atestado nos diálogos, consistiria essencialmente nos seguintes três vectores:

$\left.1^{\circ}\right)$ a vinculação da teoria das ideias a dois princípios mais fundamentais,

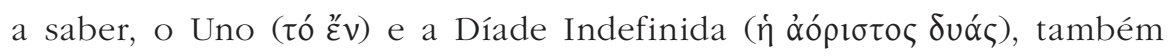

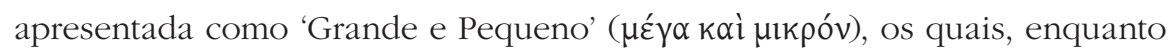
respectivamente princípios formal e material, seriam a causa tanto do sensível quanto do inteligível, bem como, na sua divergência, o fundamento do bem e do mal;

$2^{\circ}$ ) o reconhecimento de três tipos de números, a saber, os números sensíveis, as ideias de números ou 'números ideais' e, entre ambos, os 'intermediários matemáticos' ( $\tau \grave{\alpha} \mu \alpha \theta \eta \mu \alpha \tau \imath \kappa \alpha ́)$;

$3^{\circ}$ ) a identificação das ideias com números.

É fundamentalmente a partir destes três tópicos (a que, por comodidade, podemos chamar a 'doutrina dos princípios', a 'teoria dos intermediários' e a 'doutrina das ideias-números') que os intérpretes que valorizam as

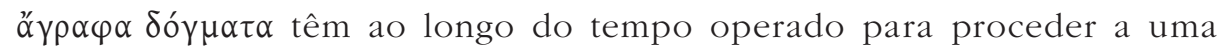
reconstrução da metafísica platónica 'oral'.

10 Ver principalmente Metaph. I 6, 9; XIII 4-8; XIV; De an. I 2, 404b16-30; mas cf. Metaph. VII 2, 1028b16-32; 11, 1036b12-17; XII 8, 1073a18-22; e, bem entendido, os textos atribuídos ao De bono, frs. 27-31 Rose. 
Modernamente, o grande impulso foi dado pela dissertação de Léon Robin (1908), La théorie platonicienne des Idées et des Nombres d'après Aristote, a qual se propôs efectuar uma primeira tentativa nesse sentido, usando exclusivamente os depoimentos aristotélicos e sem os cotejar, portanto, com os diálogos platónicos, embora sem ter ainda a intenção de opor uns e outros nem de sobrevalorizar aqueles sobre estes, como será característico dos defensores posteriores do Platão 'esotérico'. E de facto, mais tarde, na sua obra de 1935, intitulada Platon, veio aplicar os seus resultados ao estudo directo dos escritos platónicos, como havia, aliás, prometido no primeiro texto.

A investigação de Robin - seguida, à época, por alguns poucos, como Heinrich Gomperz, no seu contributo ao VII Congresso Internacional de Filosofia (1930) - teve, a prazo, uma extraordinária influência na exegese platónica do século passado e, em particular, na discussão em torno desta questão, a qual se impôs a partir daí como um problema em aberto.

Neste sentido, podem distinguir-se na actualidade três tendências perante

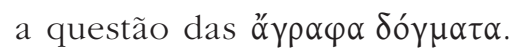

A primeira, cuja matriz se encontra na colossal obra de Harold Cherniss (1944), Aristotle's Criticism of Plato and the Academy, e também nas três conferências publicadas sob o título The Riddle of the Early Academy (1962), tem uma postura totalmente negativa em relação a este problema. A seu ver, não existe nenhum testemunho independente e fiável da existência de um ensino oral continuado por parte de Platão. Considera que os relatos de Aristóteles não têm qualquer valor histórico, pois a sua única fonte foi, tal como é ainda para nós, os próprios diálogos de Platão e que, sendo um filósofo sistemático e não um historiador da filosofia, a sua descrição é sempre feita do ponto de vista da sua própria doutrina, o que acarreta, de uma perspectiva estritamente doxográfica, que tal descrição está eivada de erros, omissões e deficientes compreensões.

Nos exactos antípodas desta posição, encontra-se a chamada 'escola de Tübingen' - de Hans-Joachim Krämer, Konrad Gaiser e, mais recentemente, Thomas Szlezak e sobretudo o infatigável Giovani Reale -, para quem a verdadeira filosofia platónica é a descrita por Aristóteles, a qual constitui a vertente 'esotérica' de um ensinamento desenvolvido original e 
constitutivamente por Platão, ao lado do magistério 'exterior' e 'exotérico' dos diálogos, caracterizado repetidamente pelo próprio como um mero jogo $\left(\pi \alpha 1 \delta_{1} \alpha\right)$. Os seus supostos radicam numa determinada interpretação das críticas platónicas à escrita e dos testemunhos aristotélicos e peripatéticos em geral: daquelas, retiram estes autores o primado da oralidade perante a escrita, a desvalorização desta e o seu carácter 'exotérico'; destes, retiram a substância do ensino 'esotérico', e portanto real, de Platão, onde avulta a 'doutrina dos princípios' (Prinzipienlebre) como ontologia hierárquica e processional.

Finalmente, uma terceira tendência, intermédia entre as anteriores, mas mais difusa e heterogénea, tende a aceitar o testemunho aristotélico como rigoroso para um último período do pensamento platónico, posterior à redacção das Leis $^{11}$, ou então a reinterpretá-lo como um repositório em linguagem aristotélica da filosofia dos últimos diálogos ${ }^{12}$.

Perante estas três linhas de tematização, o importante não é optar, nem tão-pouco propor uma nova alternativa. Uma vez que os diálogos de Platão foram ameaçados como testemunho fiável da sua filosofia, o importante é, antes, verificar qual a magnitude da devastação que a ameaça possa ter sobre o nosso conhecimento dela.

Basicamente, trata-se de, sem intervir na discussão das alegações e argumentos de cada uma daquelas linhas de interpretação e tomando apenas em consideração a própria obra platónica, tentar estabelecer quais as garantias que ela nos dá de um acesso genuíno ao pensamento do seu autor e, concomitantemente, que dados nos oferece para avaliar um qualquer projecto de reconstrução desse pensamento que se afirme como exterior aos diálogos.

11 É a posição do próprio Robin, bem como a de Stenzel (1933) e de Ross (1951). Ver também Stefanini (1949, II, 352-360), Cornford (1932) e a revisão de De Vogel (1988; 1972, 205 ss.).

12 Cf. Sayre (1983), que encontra a concretização da descrição aristotélica na última parte do Parménides e principalmente no Filebo, consideradas por ele as últimas obras de Platão. Para formas mitigadas destas tendências, veja-se a obra citada de Maria-Dominique Richard (1986, 43-47), bem assim como para outros representantes de cada uma delas (cf. 1986, 27 ss.). Uma proposta curiosa é a de Gregory Vlastos, para quem as ditas 'doutrinas não-escritas' seriam apenas aquelas que Platão pura e simplesmente havia decidido não escrever, por as não ter suficientemente amadurecido (cf. 1981, 397-398). 
Nesta direcção, impõe-se desde logo uma constatação. Considerando que metade da vida filosófica de Platão se passou no interior da Academia, cuja prática, embora desconhecida, podemos justificadamente aproximar, nem que seja tendencialmente, do programa descrito no livro VII da República, torna-se difícil excluir à partida a possibilidade de um ensino platónico exercido oralmente. Mais do que isso, torna-se problemático negar que, à luz das suas reiteradas críticas à escrita, bem como do modelo dialógico tacitamente proposto e efectivamente ilustrado pelas obras platónicas e da própria opção por esta forma como paradigma de comunicação pedagógica, semelhante ensino seria necessariamente o mais importante, em especial na sua articulação com o ensino escrito nos diálogos.

Todavia, na presunção de tal existência ${ }^{13}$, as questões que naturalmente se impõem são as seguintes: será possível aceder ao conteúdo desse ensino? Se sim, de que modo? Se não, que consequências se retiram para o nosso acesso à filosofia platónica, comprometido como está pelo duplo obstáculo de um ensino oral irrecuperável e de um ensino escrito aparentemente destituído de valor?

A primeira questão teria à partida uma resposta positiva, aceite a

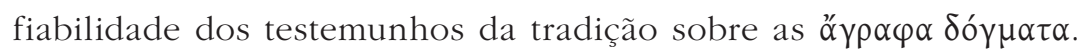

Contudo, o problema que se coloca é o de saber se um conjunto de testemunhos desse tipo, independentemente da sua natureza e conteúdo, passa ele próprio o crivo que condena os diálogos platónicos, enquanto eles são justamente depoimentos escritos.

Com efeito, o problema de raiz que afecta toda e qualquer tentativa de

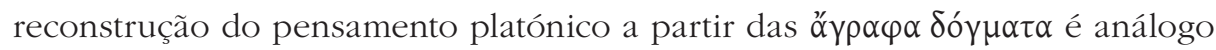
àquele que essa mesma tentativa invoca, no seu esforço para se justificar como pertinente, contra os diálogos de Platão: é que, tal como estes, tal recontrução não tem por base testemunhos orais, mas testemunhos escritos

13 Que, aliás, mesmo os mais decididos continuadores de Cherniss neste ponto se vêem forçados a reconhecer em tese (cf. Vlastos, 1981, 397-398; Allen, 1970, 144, n. 1). 
e, na verdade, ao contrário deles, testemunhos em segunda mão, ainda que alegadamente de origem oral.

Ora será que esta sua alegada origem oral é suficiente para contradizer a obra platónica na sua aspiração a único testemunho autorizado da filosofia platónica?

Parece que não.

É que - como tem sido insuficientemente observado nas críticas platónicas à escrita - o que caracteriza o modelo que aí alternativamente se propõe não é tanto a sua oralidade qua tale, mas aquilo que tal oralidade pressupõe: o exercício do diálogo à maneira socrática ${ }^{14}$, a convivência continuada, e esforçada, com o objecto de estudo ${ }^{15}$, um conjunto de requisitos pessoais entre os quais avulta a 'congenialidade com o objecto'16 e o exercício, individual e comunitário, de um conjunto de funções intelectuais e de vida ${ }^{17}$. Ora, nenhuma destas dimensões pode ser transmitido através da escrita, não, obviamente, porque seja oral, mas porque é do domínio de um fazer e não de um dizer, ainda quando esse fazer se realize também através de um dizer.

É isto justamente que significa declarar que estas dimensões estão pressupostas na oralidade. Não que elas próprias sejam 'orais', mas que só num registo de oralidade, isto é, de vida, tais dimensões podem verdadeiramente concretizar-se. Nas críticas platónicas à escrita, 'escrita' não alude apenas a um modo deficitário de dizer, mas ocorre como metáfora de um pensamento morto, inútil e desenraizado, porque truncado do conjunto de realizações vivas que constituem a condição da sua finalidade filósofica.

Todavia, se assim é, um suposto ensino oral de Platão seria ele próprio inseparável de todos estes requisitos: e essa, precisamente, a razão do seu ser oral.

Pelas suas próprias características, os conteúdos de um tal ensino, quaisquer que eles fossem, não poderiam ser autonomizados e abstraídos

14 Cf. Ep. VII 344b.

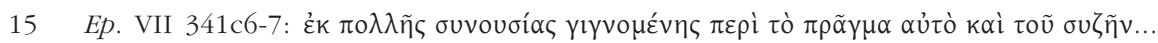

16 Ep. VII 343e6-7. Mas ver, em geral, 342a-344c e cf. 340d.

17 Cf. Phdr. 274b ss e Lg. XII 968ce. 
da sua condição de possibilidade, a saber, o diálogo e todas aqueles vectores de um fazer que justamente só logram ser aprendidos fazendo-se. Por isso, qualquer tentativa de os retomar por escrito, seja, em primeira mão, nos diálogos, seja, em segunda mão, nas denominadas 'doutrinas não-escritas', estaria sempre condenado ao fracasso, uma vez que nenhum daqueles requisitos que configuram o modo de transmissão de um ensino oral platónico, isto é, aquele modo apenas a partir do qual seria possível segundo Platão abordar as 'coisas sérias', como lhes chama na Carta VII ${ }^{18}$, pode ele próprio ser recuperado.

Nesta medida, querer reatar o ensinamento platónico oral nos termos enunciados afigura-se perigosamente vicioso.

Vicioso, em primeiro lugar, porque se alega a inadequação da escrita para dar a preferência a um património oral, mas é por intermédio de testemunhos escritos que se pretende aceder a esse património.

Vicioso, em segundo lugar, porque, se há ensino oral para Platão, é justamente porque tal ensino não pode ser escrito e, portanto, não há onde nem como recebê-lo.

E vicioso, em terceiro lugar, porque tendo Platão escrito - o que para quem mantém ao mesmo tempo um ensino oral significa: tendo escrito tudo o que presumivelmente pode ser escrito - se dá preferência a uma escrita exterior, em detrimento daquela que sabe e estabelece os limites, bem como a forma e o conteúdo possível, disso que precisamente pode ser escrito.

Ora, para Platão, quaisquer doutrinas não-escritas não seriam tal por uma incapacidade sua em escrevê-las, mas por elas mesmas não serem 'escrevíveis'. E, portanto, não as podendo encontrar na escrita platónica, seria do mesmo modo impossível, de uma perspectiva igualmente platónica, encontrá-las também em qualquer outro escrito.

E isto não decorre apenas da lógica do caso: é, pelo contrário, o próprio Platão quem o assegura, quando, após negar a autoria sobre qualquer

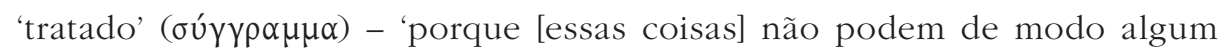

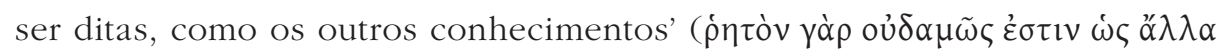
$\mu \alpha \theta \eta \dot{\mu} \alpha \tau \alpha)$ - considera que, a fazer-se, seria melhor que ele surgisse do seu 
punho do que do de outro qualquer ${ }^{19}$. De resto, todas as recriminações ao jovem Dionísio por ter ensaiado um tal empreendimento deixam claro que uma obra com essas características, isto é, de exposição escrita do que só pode efectivar-se em debate oral, é de nulo valor filosófico, em particular enquanto alegado registo do ensinamento platónico. Daí, portanto, que, do ponto de vista da filosofia platónica, só pudesse ter, no máximo, um interesse meramente doxográfico, onde as doutrinas recenseadas estariam entretanto já mortas, para retomar a linguagem de há pouco, sem qualquer virtualidade filosófica e pedagógica.

Mas será que, mesmo de um ponto de vista doxográfico, tal registo poderia oferecer alguma credibilidade?

Quer dizer, será que, mesmo sendo para Platão de 'pouco ou nenhum valor', como a sabedoria humana para Sócrates na Apologia ${ }^{20}$, o conhecimento de tais doutrinas poderia ter para nós o valor, puramente historiográfico, de permitir o acesso ao conteúdo autêntico do magistério platónico?

É o que poderemos ajuizar revendo com mais cuidado as reservas que Platão enuncia na Carta VII contra a escrita.

De facto, tem-se acentuado excessivamente neste contexto a preocupação 'secretista', ou, de outro modo, 'elitista', da passagem, esquecendo com isso as outras e mais fundamentais razões que o filósofo aí avança.

Recorrendo directamente ao texto, podemos verificar que essas razões são de cinco ordens:

$1^{\text {a) }}$ a indizibilidade do próprio objecto, nos termos acima transcritos ${ }^{21}$;

$2^{\text {a) }}$ a deficiência dos quarto modos, ou níveis, de conhecimento (ővo $\alpha$,

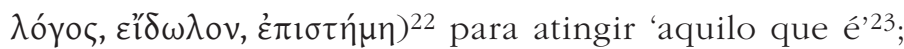

$3^{\text {a) }}$ a inconveniência de uma divulgação indiscriminada ao grande público ${ }^{24}$;

19 Cf. Ep. VII 341cd. Esta última nota foi adequadamente apontada por Cherniss (1962, 12-13) e por De Vogel (1988, 16). Mas cf. também Allen (1970, 144-145).
20 Ap. 23a.
21 Ep. VII 341c.
22 Ep. VII 342b.
23 Ep. VII 343bc.
24 Ep. VII 341de, 344cd. 
$4^{\mathrm{a}}$ ) o risco de, uma vez exposto o conhecimento, o abrir à refutação e à polémica $^{25}$;

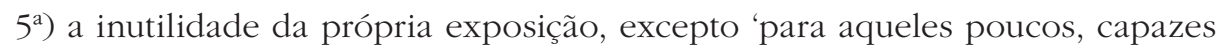
de descobrir por si mesmos através de uma pequena indicação' ( $\tau ı \sigma ı v$

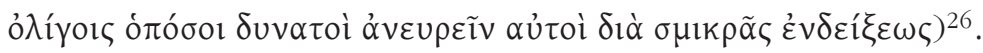

Ora, se as terceira e quarta razões não constituiriam obstáculo a um

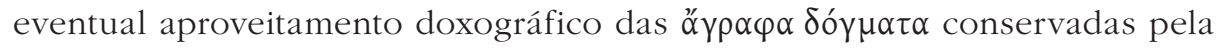
tradição, o mesmo não acontece com a primeira e a segunda, que muito claramente vinculam a inadequação da escrita a uma mais radical deficiência da linguagem e também de cada um dos vários modos de conhecimento, mostrando que as críticas da Carta VII não afectam apenas a palavra escrita, mas também a palavra oral, e que, portanto, não há, à partida, maior fiabilidade nos testemunhos 'orais' da tradição do que nos diálogos escritos de Platão ${ }^{27}$.

Todavia, se atentarmos de novo nas condições do ensino oral atrás enunciadas, verificamos que elas nos dão um motivo decisivo para rejeitar as alegadas doutrinas não-escritas de Platão na sua pretensão de se substituir aos diálogos como forma de acesso à 'verdadeira' doutrina platónica.

É que, na verdade, todas aquelas condições convergem numa mesma direcção, que é a designação do diálogo, nos termos enunciados, como veículo filosófico e pedagógico por excelência.

Ora o que caracteriza as doutrinas não-escritas atribuídas a Platão, na sua especificidade, material e formal, e bem assim as tentativas reconstrutivas modernas, é o carácter propriamente dogmático do ensino exposto, denunciando, nesse seu mesmo carácter, a sua origem não platónica e, portanto, a sua inadequação como relatório, sequer doxográfico, do pensamento de Platão.

\footnotetext{
25 EP. VII 343d.

26 Ep. VII 341e.

27 Esta observação constitui igualmente o tema central do artigo de Sayre (1988), que a demonstra amplamente, recorrendo não só à Carta VII, como a alguns dos diálogos-chave. A mesma tese perpassa também pelo texto de Desjardins (1988, 111), e De Vogel (1988, 18).
} 
Com efeito, se o ensino é, para Platão, necessariamente diálogo, nunca as questões presumivelmente abordadas no seu ensino, justamente oral, poderiam constituir 'sistema', ou como se queira chamar à estrita organização escolar sob a qual se apresentam as 'doutrinas não-escritas'.

Com isto não se nega, evidentemente, a eventual articulação dos tópicos que delas constam com o pensamento platónico, mas sim a sua coadunação com o espírito platónico que as autenticaria na origem, deixando adivinhar que a sua possível ligação a esse pensamento é já débil, porque descontextualizado.

Significará isto então que, condenada a escrita e impossibilitado um

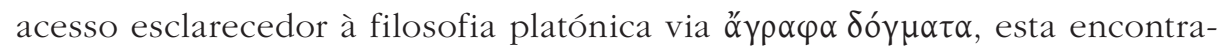
se perdida para a filosofia?

A imediata avalição dos termos permite uma resposta negativa.

Em Platão, a escrita nunca é propriamente negada, senão que desvalorizada perante o diálogo e tudo o que ele pressupõe e comporta, nos termos anteriormente indicados ${ }^{28}$. Porém, tal desvalorização envolve, ao mesmo tempo, a aclaração do estatuto que lhe incumbe e, em certo sentido, a enunciação da sua própria necessidade.

É o que a própria Carta VII sugere, quando, na quinta objecção apontada à escrita, circunscreve o estatuto que lhe pode caber como lugar e ponto de partida de um projecto de saber.

Uma exposição escrita, diz-nos ela, é absolutamente inútil, salvo para 'aqueles poucos' que são 'capazes de descobrir por si mesmos através de uma pequena indicação'.

Ou seja: a escrita é, enquanto tal, incapaz de conduzir à verdade, porque esta tem de ser descoberta 'por cada um'. No entanto, tal como o diálogo oral, ela pode constituir também uma 'pequena indicação' para o despertar dessa descoberta, sob a condição, pode supor-se, de se apresentar não como um discurso (Fedro) ou um tratado (Carta VII), mas como, ela própria, um diálogo. 
Nesta medida, do mesmo modo que Sócrates no diálogo oral, também Platão, através de Sócrates, num diálogo escrito, pode induzir a ouıkpò

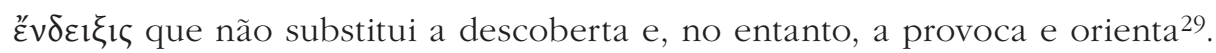

Esta a possibilidade de revalorizar a obra escrita de Platão: tomá-la no seu todo, tal como ao próprio diálogo real, como uma 'pequena indicação' para a descoberta da verdade.

A esta luz, torna-se justificado tomar os diálogos escritos como único testemunho fiável do ensinamento platónico, assim recuperando, na sua literalidade, a brutal declaração de Field (1934, 283):

Em qualquer caso, falando pragmaticamente, Platão e os diálogos platónicos são idênticos. A única filosofia platónica à qual temos acesso é a filosofia dos diálogos e é essa filosofia que tem sido uma influência e uma inspiração para sucessivas gerações de pensadores.

Nesta medida, a validade do corpus escrito em nada diminui a evidência de um ensino não-escrito, senão que é dela devedora.

O que ficou escrito de Platão é apenas a prescrição do que deve ser feito e a ilustração desse fazer, não a sua efectivação mesma. A escrita pode indicar o que há a fazer, mas não se pode substituir a esse fazer, que, justamente enquanto tal, nunca pode ser só escrito ou só escrita, mas tem de ser feito.

O a-fazer, que para Platão constitui o essencial e, a limite, o único desígnio do filosofar, não se faz apenas na escrita ou escrevendo. Faz-se fazendo e esse fazer escapa por essência à escrita ${ }^{30}$.

29 Para uma semelhante homologação do diálogo escrito e do diálogo oral, cf. Sayre (1988, 103 ss). É o que, na sua própria linguagem, também Lutoslawski já havia concluído: 'We have therefore no reason to suppose that any part of his philosophy has been fully expressed in his works, though we may look at these as sufficient evidence of his thought, enabling us to acquire a fair and probable conception of his theories' (Lutoslawski, 1897, 518).

30 Charles Kahn apreende bem este ponto, quando afirma: 'At the level of Plato's philosophical project this whole series of works (including not only most of the 'Socratic' dialogues but even the Symposium, Phaedo, and Republic) was conceived as a vast protreptic to the philosophical life, not as a literary substitute for the living practice. The dialogues are designated to iniciate the reader into the world of Platonic philosophy, and that means not simply the world of philosophical books but the life of philosophical study and discussion. 
Daí o valor dos diálogos como 'pequena indicação'. Pequena, não porque isso é tudo o que pode ser dito por escrito, mas porque isso é tudo o que pode ser dito tout cour. Tudo o resto tem de ser feito. E é por isso que os diálogos platónicos são deveras, não por acidente, mas por essência, tudo o que subsiste do ensino de Platão.

É esta identidade essencial e inultrapassável entre a filosofia dos diálogos e a filosofia de Platão que Hegel exemplarmente enuncia, quando diz (18251826: vide Vieillard-Baron, 1976, 100):

Este é o esotérico da filosofia platónica, o outro é o exotérico; mas não se deve tomar esta diferença como se Platão tivesse duas filosofias: uma para o mundo, para o vulgo; a outra, a interior, reservada para os íntimos. O esotérico é o especulativo, que está escrito e impresso e, no entanto, permanece oculto para aqueles que não têm interesse para se darem a trabalhos. Não é um segredo e, todavia, está oculto.

\section{BIBLIOGRAFIA}

Albert, K. (2008). Weg und Wesen abendlandischen Philosophierens. Darmstadt: Wissenschaftliche Buchgesellschaft.

(1996). Einführung in die philosophische Mystik. Darmstadt: Wissenschaftliche Buchgesellschaft. (1980). Griechische Religion und platonische Philosophie. Hamburg: Meiner.

Allen, R. E. (1970). Plato's Euthyphro and the Earlier Theory of Forms. London: Routledge and Kegan Paul.

Annas, J. (1974). Forms and First Principles. Phronesis, 19, 257-283.

Berti, E. (1994). Le dottrine platoniche non scritte 'intorno al bene' nelle testimonialize di Aristotele. In G. Reale (ed.), Verso una nuova immagine di Platone (251-294). Milano: Vita e Pensiero. Brisson, L. (1995). Premises, Consequences and Legacy of an Esotericist Interpretation of Plato. Ancient Philosophy, 15, 117-134.

(...) The literary form of the Socratic dialogue was the natural choice for porsuing the work that Socrates had begun.' (Kahn, 1986, 11) Também Robinson tinha já apontado nesta direcção, quando, após sublinhar a identidade da filosofia com a dialéctica em Platão, declara: 'Dialectic is a skill to be acquired, much more than it is a body of propositions to be learnt. Plato does not regard the philosopher's or the dialectician's work as the construction or accumulation of something external to himself, but as the alteration of his own personality in a fundamental way, as character-building. The nature of the alteration is vaguely indicated by the phrase 'becoming wise'.' (Robinson, 1953, 74) 
Burnet, J. (1899-1907). (ed.). Platonis Opera. 1. Tetralogia I: Euthyphro, Apologia Socratis, Crito, Phaedo. Tetralogia II: Cratylus, Theaetetus, Sophista, Politicus. 2. Tetralogia III: Parmenides, Philebus, Symposium, Phaedrus. Tetralogia IV: Alcibiades I, Alcibiades II, Hipparchus, Amatores. 3. Tetralogia V: Theages, Charmides, Laches, Lysis. Tetralogia VI: Euthydemus, Protagoras, Gorgias, Meno. Tetralogia VII: Hippias maior, Hippias minor, Io, Menexenus. 4. Tetralogia VIII: Clitopho, Res publica, Timaeus, Critias. 5. Tetralogia IX: Minos, Leges, Epinomis, Epistulae, Definitiones, Spuria. Oxford: Clarendon Press.

Caeiro, A. (2014). (ed.). Obras Completas de Aristóteles. X: Fragmentos dos Diálogos e Obras Exortativas. Revisão científica de A. P. Mesquita. Lisboa: INCM.

Cherniss, H. (1962). The Riddle of the Early Academy. New York: Russell and Russell.

(1944). Aristotle's Criticism of Plato and the Academy, I. Baltimore: The Johns Hopkins Press.

Cornford, F. M. (1932). Mathematics and Dialectic in Plato's Republic VI-VII. Mind, 41, 37-52. Reeditado em R. E. Allen (1965). (ed.), Studies in Plato's Metaphysics (61-95). London/New York: Routledge.

Desjardins, R. (1988). Why Dialogues? Plato's Serious Play. In C. L. Griswold Jr. (ed.), Platonic Writings, Platonic Readings (110-125). New York/London: Routledge.

De Vogel, C. J. (1988). Plato: The Written and Unwritten Doctrines. Fifty years of Plato studies, 1930-1980. In C. De Vogel (1988), Rethinking Plato and Platonism (2a ed.) (3-56). Leiden: E. J. Brill.

(1972). Was Plato a Dualist?. Theta-Pi, 1, 4-60. Reeditado em C. De Vogel (1988), Rethinking Plato and Platonism (2a ed.). (159-212). Leiden: E. J. Brill.

Diels, H. (1895). (ed.). Simplicii in Aristotelis Physicorum libros quattuor posteriores commentaria. Berolini: Typis et impensis Georgii Reimeri.

(1882). (ed.). Simplicii in Aristotelis Physicorum libros quattuor priores commentaria. Berolini: Typis et impensis Georgii Reimeri.

Duke, E. A. et al. (1995). (ed.). Platonis Opera. I: Euthyphro, Apologia Socratis, Crito, Phaedo, Cratylus, Theaetetus, Sophista, Politicus. Oxford: Clarendon Press.

Ferber, R. (2007). Warum hat Platon die 'ungeschriebene Lebre' nicht geschrieben?. München: Beck. Field, G. C. (1934). Great Thinkers. (II) Plato. Philosophy, 35, 282-292.

Fine, G. (1993). On Ideas. Aristotle's Criticism of Plato's Theory of Forms. Oxford: Clarendon Press. Finlay, J. N. (1978). Plato and Platonism: An Introduction. New York/Toronto: Times Books.

(1974). Plato: The Written and Unwritten Doctrines. London/New York: Humanities Press.

Gadamer, H.-G. (1968). Platons ungeschriebene Dialektik. In H.-G. Gadamer et al. (eds.), Idee und Zabl. Abhandlungen der Heidelberger Akademie der Wissenschaften (9-30). Heidelberg: Heidelberger Akademie der Wissenschaften. Reeditado em H.-G. Gadamer (1980). Dialogue and Dialectic: Eight Hermeneutical Studies on Plato (124-155). New Haven: Yale University Press, trad. P. C. Smith.

Gadamer, H.-G. \& Reale, G. (1998). La nuova interpretazione di Platone. Un dialogo tra Hans-Georg Gadamer e la scuola di Tubinga. Milano: Rusconi, trad. G. Girgenti.

Gaiser, K. (1998). Testimonia Platonica. Le antiche testimonianze sulle dottrine non scritte di Platone. Milano: Vita e Pensiero (originalmente publicado como apêndice a Gaiser, 1963).

(1991). La metafisica delta storia in Platone: con un saggio sulla teoria dei principi e una raccolta in edizione bilingue dei testi platonici sulla storia (2a ed.). Milano: Vita e Pensiero, trad. G. Girgenti. 
(1980). Plato's Enigmatic lecture 'On the Good'. Phronesis, 25, 5-37.

(1963). Platons ungeschriebene Lebre. Studien zur systematischen und geschichtlichen Begründung der Wissenschaft in der Platonischen Schule. Stuttgart: Ernst Klett. Edição italiana: (1994) La dottrina non scritta di Platone: studi sulla fondazione sistematica et storica delle scienze nella scuola platonica. Milano: Vita e Pensiero, trad. V. Cícero.

Gomperz, H. (1931). Plato's System of Philosophy. In G. Ryle (ed.), Proceedings of the Seventh International Congress of Philosophy (426-431). London: Oxford University Press. Reeditado em H. Gomperz (1953). Philosophical Studies (119-124). Boston: Christopher Publishing House.

Guthrie, W. K. C. (1978). A History of Greek Philosophy. Cambridge: Cambridge University Press , vol. V.

(1975). A History of Greek Philosophy. Cambridge: Cambridge University Press, vol. IV.

Hegel, G. W. F. (1825-1826): vide Vieillard-Baron (1976).

Isnardi Parente, M. (1998). Testimonia platonica: per una raccolta delle principali testimonianze sui legòmena agrafa dogmata di Platone. Testimonianze di età ellenistica e di età imperiale. Roma: Accademia Nazionale dei Lincei.

(1997). Testimonia platonica: per una raccolta dei principali passi della tradizione indiretta riguardante i legòmena agrafa dogmata. Le testimonianze di Aristotele. Roma: Accademia Nazionale dei Lincei.

Kahn, C. H. (1986). Plato's Methodology in the Laches. Revue Internationale de Philosophie, 40, 7-21. Krämer, H. J. (1986). La nuova immagine di Platone. Napoli: Bibliopolis, trad. A. Pensa.

(1982). Platone e i fondamenti della metafisica. Saggio sulla teoria dei principi e sulle dottrine non scritte di Platone con una raccolta dei documenti fondamentali in edizione bilingue e bibliografia. Milano: Vita e Pensiero, trad. G. Reale. Edição inglesa: (1990) Plato and the Foundations of Metaphysics: A Work on the Theory of the Principles and Unwritten Doctrines of Plato with a Collection of the Fundamental Documents. Albany: SUNY Press, trad. J R. Catan.

(1972). Platonismus und hellenistische Philosophie. Berlin: De Gruyter.

(1964a). Retraktationem zum Problem des esoterischen Platon. Museum Helveticum, 21, 137-167.

(1964b). Der Ursprung der Geistmetaphysik. Untersuchungen zur Geschichte des Platonismus zwischen Platon und Plotin. Amsterdam: Schippers.

(1959). Arete bei Platon und Aristoteles. Zum Wesen und zur Geschichte der platonischen Ontologie. Heidelberg: Carl Winter Universitätsverlag.

Kraut, R. (1992). (ed.). The Cambridge Companion to Plato. Cambridge: Cambridge University Press. Lutoslawski, W. (1897). The Origin and Growth of Plato's Logic, with an account of Plato's Style and the Chronology of his Writings. London/New York/Bombay: Longmans, Green \& Co. Reedição: (1983) Hildesheim/Zürich/New York: Georg Olms Verlag.

Mesquita, A. P. (1995). Reler Platão. Ensaio sobre a Teoria das Ideias. Lisboa: IN-CM.

Minio-Paluello, L. et al (1961-1991). (ed.). Aristotelis. Oxford: Oxford University Press.

Nikulin, D. (2012). (ed.). The Other Plato. The Tübingen Interpretation of Plato's Inner-Academic Teachings. New York: SUNY.

Perine, M. (2011). O Filebo de Platão e as Doutrinas Não Escritas. Educação e Filosofia Uberlândia, 25, 149-171.

(2007). A Tradição Platónica Indireta e suas Fontes. Dissertatio, 25, 11-40. 
Pesce, D. (1990). Il Platone di Tubinga. E due studi sullo Stoicismo. Brescia: Paideia.

Reale, G. (2008). Autotestimonianze e rimandi dei Dialoghi di Platone alle Dottrine non sritte: testo greco a fronte. Milano: Bompiani.

(2003). Per una nuova interpretazione di Platone: rilettura della metafisica dei grandi dialoghi alla luce delle 'Dottrine non scritte' (21a ed.). Milano: Università Cattolica del Sacro Cuore. Edição portuguesa: (1997) Para uma Nova Interpretação de Platão: Releitura da Metafísicas dos Grandes Diálogos à Luz das 'Doutrinas Não-Escritas'. São Paulo: Loyola, trad. M. Perine.

(2001). Il pensiero antico. Milano: Vita e Pensiero.

(1997a). (ed.). Aristotele. Metafísica. Milano: Rusconi. Edição portuguesa: (2001). São Paulo: Loyola, trad. M. Perine.

(1997b). Platone. Alla ricerca della sapienza segreta. Milano: Rizzoli.

(1994). (ed.). Verso una nuova immagine di Platone. Milano: Vita e Pensiero.

(1993). Il concetto di filosofia prima e l'unità della Metafisica di Aristotele (6a ed.). Milano:

Vita e Pensiero.

(1991). (ed.). Platone. Tutti gli scritti. Milano: Rusconi.

(1980-1982). Storia della filosofia antica. I: Dalle origini a Socrate. II: Platone e Aristotele.

III: I sistemi dell'età ellenistica. IV: Le scuole dell'età imperiale. V: Lessico, indici e bibliografia. Milano: Vita e Pensiero.

Reale, G. \& Catan, J. R. (1990). A History of Ancient Philosophy: Plato and Aristotle. Albany: SUNY Press.

Richard, M.-D. (1986). L'enseignement oral de Platon. Une nouvelle interprétation du platonisme. Paris: Les Éditions du Cerf.

Rios, R. (1954). (ed.). Aristoxeni elementa harmonica. Roma: Polygraphica.

Robin, L. (1935). Platon. Paris: Félix Alcan.

(1908). La théorie platonicienne des Idées et des Nombres d'après Aristote. Étude historique et critique. Paris: Alcan.

Robinson, R. (1953). Plato's Earlier Dialectic (2a ed.). Oxford: Clarendon Press.

Rodriguez-Grandjean, P. (1998). Philosophy and Dialogue: Plato's Unwritten Doctrines from a Hermeneutical Point of View. In Twentieth World Congress of Philosophy in Boston (Mass.) from August 10-15. Acedido a 12 de junho de 2017, em http://www.bu.edu/wcp/Papers/ Anci/AnciRodr.htm

Ross, W. D. (1955). Aristotelis fragmenta selecta. Oxford: Oxford University Press.

(1951). Plato's Theory of Ideas. Oxford: Clarendon Press.

(1886). Aristotelis qui ferebantur librorum fragmenta. Leipzig: Teubner.

Sayre, K. M. (1993). Hans J. Kraemer: Plato and the Foundations of Metaphysics. Ancient Philosophy, $13,167-184$.

(1988). Plato's Dialogues in Light of the Seventh Letter. In C. L. Griswold Jr. (ed.), Platonic Writings, Platonic Readings (93-109). New York/London: Routledge.

(1983). Plato's Late Ontology. A Riddle Resolved. Princeton: Princeton University Press.

Stefanini, L. (1949). Platone, I-II (2a ed.). Padova: Antonio Milani.

Stenzel, J. (1933). Zabl und Gestalt bei Platon und Aristoteles (2a ed.). Leipzig/Berlin: Teubner.

Szlezak, T. A. (2004), Platon und die Schriftlichkeit der Philosophie. II: Das Bild des Dialektikers in Platons späten Dialogen. Berlin: De Gruyter.

(1999). Reading Plato. New York: Routledge.

(1985). Platon und die Schriftlichkeit der Philosophie. I: Interpretationen zu den 


\section{DOUTRINAS NÃO-ESCRITAS}

frühen und mittleren Dialogen. Berlin: De Gruyter. Edição italiana: (1989) Platone e la scittura della filosofia: analisi di struttura dei dialoghi della giovinezza e della maturità alla luce di un nuovo paradigma ermeneutico. Milano: Vita e Pensiero, trad. G. Reale.

Tigerstedt, E. N. (1977). Interpreting Plato. Uppsala: Almqvist \& Wiksell International.

(1974). The Decline and Fall of the Neoplatonic Interpretation of Plato. An Outline and Some Observations. Helsinki: Societas Scientariarum Fennica.

Vieillard-Baron (1976) (trad.). G. W. F. Hegel. Leçons sur Platon 1825-1826, texte inédit présenté en bilingue. Paris: Aubier.

Vlastos, G. (1981). Platonic Studies (2a ed.). Princeton: Princeton University Press.

(1971). (ed.). The Philosophy of Socrates. A Collection of Critical Essays. Garden City: Doubleday.

(1970). (ed.). Plato. A Collection of Critical Essays. I: Metaphysics and Epistemology. II: Ethics, Politics, and Philosophy of Art and Religion. Garden City: Doubleday.

(1963). H. J. Kraemer: Arete bei Platon und Aristóteles. Gnomon, 35, 641-655. Reeditado, com um apêndice, em G. Vlastos. Platonic Studies (2a ed.) (379-403). Princeton: Princeton University Press.

Wippern, J. (1972). (ed.). Das Problem der ungeschriebenen Lehre Platons: Beiträge zum Verständnis der Platonischen Prinzipienphilosophie. Darmstadt: Wissenschaftliche Buchgesellschaft. 